\title{
Using First-Order Logic to Reason about Submodule Construction*
}

\author{
Gregor v. Bochmann \\ School of Information Technology and Engineering (SITE), University of Ottawa, Canada \\ bochmannesite.uottawa.ca
}

\begin{abstract}
We consider the following problem: For a system consisting of two components, the behavior of one component is known as well as the desired global behavior. What should be the behavior of the second component such that the behavior of the composition of the two conforms to the desired behavior ? - This problem has been called "submodule construction" or "equation solving". Solutions to this problem have been described in the context of various specification formalisms and various conformance relations. This paper presents a new formulation of this problem and its solution in first-order logic. It is also shown how the solutions for submodule construction in various specification formalisms can be derived from the solution in logic. The simple proof of correctness for the logic solution is then used to justify the particular forms of solutions in the different specification formalisms, such as (a) synchronous rendezvous at several interfaces, and (b) interleaved rendezvous (labeled transition systems).
\end{abstract}

\section{Introduction}

In automata theory, the notion of constructing a product machine $\mathrm{S}$ from two given finite state machines $M_{A}$ and $M_{B}$, written $M=M_{A} \times M_{B}$, is a well-known concept (see Figure 1(a)). This notion is very important in practice since complex systems are usually constructed as a composition of smaller subsystems, and the behavior of the overall system is in many cases equal to the composition obtained by calculating the product of the behaviors of the two subsystems. Here we consider the inverse operation, called "equation solving" or "submodule construction": Given the composed system $\mathrm{M}$ and one of the components $\mathrm{M}_{\mathrm{A}}$, what should be the behavior of the second component $\mathrm{M}_{\mathrm{B}}$ such that the composition of these two components $\mathrm{M}_{\mathrm{A}}$ and $\mathrm{M}_{\mathrm{B}}$ will exhibit a behavior equal to $\mathrm{M}$. That is, we are looking for the value of $\mathrm{X}$ which is the solution to the equation $M_{A} \times X=M$ (see Figure 1(b)). Actually, since equality often cannot be realized, we are looking for the most general machine $\mathrm{X}$ which composed with $\mathrm{M}_{\mathrm{A}}$ satisfies some conformance relation in respect to $\mathrm{M}$. In this paper we consider trace inclusion as conformance relation.

A first paper of 1980 [1] (see also [2]) gives a solution to this problem for the case where the machine behavior is described in terms of LTS (communicating by

* This work was partly supported by a research grant from the Natural Sciences and Engineering Research Council of Canada. 
interleaved rendezvous). This work was later extended to the cases where the behavior of the machines is described by CSP, FSMs with queues, IOAs and synchronous FSMs. The problem has also been formulated for databases using relational algebra (see [3] for pertinent references). The main applications of this work are in the design of communication protocols, the construction of protocol converters for communication gateways, the selection of test cases of testing a module in a context, and for finding a controller for discrete event control systems [4].

The purpose of this paper is to show that, in fact, the equation solving (or submodule construction) problem can be formulated in logic. It turns out that (a) a solution with a structure similar to the solutions mentioned above exists, and (b) a proof of the correctness of this solution is quite simple, apparently much simpler than the existing proofs of correctness for the solutions in the contexts mentioned above. We show in this paper how the solutions for submodule construction in different contexts can be derived from the general solution in the logic context. The proof of correctness from the logic context can therefore be used to justify the particular forms of solutions in the contexts of different specification formalisms. In this paper we give an overview of the cases of (a) synchronous rendezvous at several interfaces, and (b) interleaved rendezvous (that is, labeled transition systems). A more detailed discussion, including examples, can be found in [3]. Other contexts are considered in [5], such as synchronous (I/O) automata with complete or partial behavior specifications, interleaving IOA with complete or partial behavior specifications, and finite state machines with queued communication, as well as relational algebra for databases. These contexts include much of the previous work mentioned above and also some not so common modeling approaches.

\section{Equation Solving in the Logic Context}

We use in this section first-order logic with typed variables. We consider a universe with three variables $X_{A}, X_{B}$, and $X_{C}$ that may take values from three domains $D_{A}, D_{B}$ and $D_{C}$, respectively. These domains may be infinite. Therefore, the set of possible value assignments to the variables is $U=D_{A} \times D_{B} \times D_{C}$. We write $x_{A}, x_{B}$, and $x_{C}$ for possible values of the variables $\mathrm{X}_{\mathrm{A}}, \mathrm{X}_{\mathrm{B}}$, and $\mathrm{X}_{\mathrm{C}}$, respectively.

We are interested in relationships between values of different variables. For instance, we may consider a relation $R \subset D_{A} \times D_{B}$ which is a subset of pairs $\left\langle x_{A}, x_{B}\right\rangle$ of values of the variables $X_{A}$ and $X_{B}$. We also use predicates to characterize sets. For instance, the relation $R$ may be characterized by a predicate $C\left(x_{A}, x_{B}\right)$ which is true exactly for those pairs $<\mathrm{x}_{\mathrm{A}}, \mathrm{x}_{\mathrm{B}}>$ that are in $\mathrm{R}$.

\section{The equation solving problem}

In the following, we are interested in three relations $\mathrm{R}_{\mathrm{A}} \subset \mathrm{D}_{\mathrm{B}} \times \mathrm{D}_{\mathrm{C}}, \mathrm{R}_{\mathrm{B}} \subset \mathrm{D}_{\mathrm{A}} \times \mathrm{D}_{\mathrm{C}}$ and $\mathrm{R}_{\mathrm{C}} \subset \mathrm{D}_{\mathrm{A}} \times \mathrm{D}_{\mathrm{B}}$. We write $\mathrm{C}_{\mathrm{A}}\left(\mathrm{x}_{\mathrm{B}}, \mathrm{x}_{\mathrm{C}}\right), \mathrm{C}_{\mathrm{B}}\left(\mathrm{x}_{\mathrm{A}}, \mathrm{x}_{\mathrm{C}}\right)$, and $\mathrm{C}_{\mathrm{C}}\left(\mathrm{x}_{\mathrm{A}}, \mathrm{x}_{\mathrm{B}}\right)$ for their respective characterizing predicates. We now consider the following proposition:

$$
\forall<\mathrm{x}_{\mathrm{A}}, \mathrm{x}_{\mathrm{B}}, \mathrm{x}_{\mathrm{C}}>\in \mathrm{U}:<\mathrm{x}_{\mathrm{B}}, \mathrm{x}_{\mathrm{C}}>\in \mathrm{R}_{\mathrm{A}} \wedge<\mathrm{x}_{\mathrm{A}}, \mathrm{x}_{\mathrm{C}}>\in \mathrm{R}_{\mathrm{B}} \Rightarrow<\mathrm{x}_{\mathrm{A}}, \mathrm{x}_{\mathrm{B}}>\in \mathrm{R}_{\mathrm{C}} \quad\left(1^{\mathrm{Rel}}\right)
$$


This proposition may be equivalently rewritten in terms of the predicates as follows:

$$
\forall<\mathrm{x}_{\mathrm{A}}, \mathrm{x}_{\mathrm{B}}, \mathrm{x}_{\mathrm{C}}>\in \mathrm{U}: \mathrm{C}_{\mathrm{A}}\left(\mathrm{x}_{\mathrm{B}}, \mathrm{x}_{\mathrm{C}}\right) \wedge \mathrm{C}_{\mathrm{B}}\left(\mathrm{x}_{\mathrm{A}}, \mathrm{x}_{\mathrm{C}}\right) \Rightarrow \mathrm{C}_{\mathrm{C}}\left(\mathrm{x}_{\mathrm{A}}, \mathrm{x}_{\mathrm{B}}\right)
$$

The problem of equation solving is the following: We assume that $R_{A}$ and $R_{C}$ are given. What are the properties of relation $R_{B}$ that ensure that proposition (1) is satisfied? - We would like to find a maximal solution $R_{B}{ }^{\max }$ to this problem, that is, $R_{B}{ }^{\max }$ together with $R_{A}$ and $R_{C}$ would satisfy (1), but any larger $R_{B} \supset \supset R_{B}{ }^{\max }$ would not satisfy this proposition.

\section{The maximal solution}

Starting from $\left(1^{\text {Pred }}\right)$, it is easy to see that the following predicate characterizes the maximal solution:

$$
\mathrm{C}_{\mathrm{B}}{ }^{\max }\left(\mathrm{x}_{\mathrm{A}}, \mathrm{x}_{\mathrm{C}}\right)=\forall \mathrm{x}_{\mathrm{B}} \in \mathrm{D}_{\mathrm{B}}: \mathrm{C}_{\mathrm{A}}\left(\mathrm{x}_{\mathrm{B}}, \mathrm{x}_{\mathrm{C}}\right) \Rightarrow \mathrm{C}_{\mathrm{C}}\left(\mathrm{x}_{\mathrm{A}}, \mathrm{x}_{\mathrm{B}}\right)
$$

The right side of this definition can be equivalently transformed in several steps as follows:

$$
\begin{array}{ll}
\forall \mathrm{x}_{\mathrm{B}} \in \mathrm{D}_{\mathrm{B}}: & \neg \mathrm{C}_{\mathrm{A}}\left(\mathrm{x}_{\mathrm{B}}, \mathrm{x}_{\mathrm{C}}\right) \vee \mathrm{C}_{\mathrm{C}}\left(\mathrm{x}_{\mathrm{A}}, \mathrm{x}_{\mathrm{B}}\right) \\
\forall \mathrm{x}_{\mathrm{B}} \in \mathrm{D}_{\mathrm{B}}: & \neg\left(\mathrm{C}_{\mathrm{A}}\left(\mathrm{x}_{\mathrm{B}}, \mathrm{x}_{\mathrm{C}}\right) \wedge \neg \mathrm{C}_{\mathrm{C}}\left(\mathrm{x}_{\mathrm{A}}, \mathrm{x}_{\mathrm{B}}\right)\right) \\
\neg \exists \mathrm{x}_{\mathrm{B}} \in \mathrm{D}_{\mathrm{B}}: & \mathrm{C}_{\mathrm{A}}\left(\mathrm{x}_{\mathrm{B}}, \mathrm{x}_{\mathrm{C}}\right) \wedge \neg \mathrm{C}_{\mathrm{C}}\left(\mathrm{x}_{\mathrm{A}}, \mathrm{x}_{\mathrm{B}}\right)
\end{array}
$$

which leads to the following equivalent expression for the maximal solution:

$$
\mathrm{C}_{\mathrm{B}}^{\max }\left(\mathrm{x}_{\mathrm{A}}, \mathrm{x}_{\mathrm{C}}\right)=\neg \exists \mathrm{x}_{\mathrm{B}} \in \mathrm{D}_{\mathrm{B}}: \mathrm{C}_{\mathrm{A}}\left(\mathrm{x}_{\mathrm{B}}, \mathrm{x}_{\mathrm{C}}\right) \wedge \neg \mathrm{C}_{\mathrm{C}}\left(\mathrm{x}_{\mathrm{A}}, \mathrm{x}_{\mathrm{B}}\right)
$$

\section{The realized subset of $\mathbf{R}_{\mathbf{C}}$}

We note that in general not all pairs $\left\langle x_{A}, x_{B}>\in R_{C}\right.$ could be "realized" by $R_{A}$ and $\mathrm{R}_{\mathrm{B}}^{\max }$.

Definition: We say that a pair $<x_{A}, x_{B}>\in R_{C}$ is realizable by $R_{A}$ and $R_{B}$ if there exist a value $x_{C} \in D_{C}$ such that $\left\langle x_{B}, x_{C}>\in R_{A}\right.$ and $\left\langle x_{A}, x_{C}>\in R_{B}\right.$.

We call the subset of $R_{C}$ that is realisable by $R_{A}$ and $R_{B}{ }^{\max }$ the maximally realisable subset of $\mathrm{R}_{\mathrm{C}}$ (or "product"), written $\mathrm{R}_{\mathrm{C}}$ prod . We therefore have

$$
<\mathrm{x}_{\mathrm{A}}, \mathrm{x}_{\mathrm{B}}>\in \mathrm{R}_{\mathrm{C}}^{\text {prod }} \text { iff } \exists \mathrm{x}_{\mathrm{C}} \in \mathrm{D}_{\mathrm{C}}:<\mathrm{x}_{\mathrm{B}}, \mathrm{x}_{\mathrm{C}}>\in \mathrm{R}_{\mathrm{A}} \wedge<\mathrm{x}_{\mathrm{A}}, \mathrm{x}_{\mathrm{C}}>\in \mathrm{R}_{\mathrm{B}}{ }^{\max }
$$

\section{The reduced maximal solution}

We consider the relation $\mathrm{R}_{\mathrm{B}}{ }^{\text {incompatible }}$ characterized by the following predicate:

$$
\mathrm{C}_{\mathrm{B}}^{\text {incompatible }}\left(\mathrm{x}_{\mathrm{A}}, \mathrm{x}_{\mathrm{C}}\right)=\neg \exists \mathrm{x}_{\mathrm{B}} \in \mathrm{D}_{\mathrm{B}}: \mathrm{C}_{\mathrm{A}}\left(\mathrm{x}_{\mathrm{B}}, \mathrm{x}_{\mathrm{C}}\right) \wedge \mathrm{C}_{\mathrm{C}}\left(\mathrm{x}_{\mathrm{A}}, \mathrm{x}_{\mathrm{B}}\right)
$$

Lemma: There is no $<x_{A}, x_{B}>\in R_{C}$ that is realizable by $R_{A}$ and $R_{B}{ }^{\text {incompatible }}$.

Proof: Let us assume that there is a pair $<x_{A}, x_{B}>\in R_{C}$ that is realizable by $R_{A}$ and $\mathrm{R}_{\mathrm{B}}{ }^{\text {incompatible }}$. According to the definition of "realizable", this implies that there is a $\mathrm{x}_{\mathrm{C}}$ $\in \mathrm{D}_{\mathrm{C}}$ such that $\left\langle\mathrm{x}_{\mathrm{B}}, \mathrm{x}_{\mathrm{C}}\right\rangle \in \mathrm{R}_{\mathrm{A}}$ and $\left\langle\mathrm{x}_{\mathrm{A}}, \mathrm{x}_{\mathrm{C}}\right\rangle \in \mathrm{R}_{\mathrm{B}}{ }^{\text {incompatible }}$. Now, the definition of $\mathrm{R}_{\mathrm{B}}{ }^{\text {incompatible }}$ implies that there is no $\mathrm{x}^{\prime}{ }_{\mathrm{B}} \in \mathrm{D}_{\mathrm{B}}$ such that $\mathrm{C}_{\mathrm{A}}\left(\mathrm{x}_{\mathrm{B}}{ }_{\mathrm{B}}, \mathrm{x}_{\mathrm{C}}\right) \wedge \mathrm{C}_{\mathrm{C}}\left(\mathrm{x}_{\mathrm{A}}, \mathrm{x}_{\mathrm{B}}{ }^{\prime}\right)$. However, this is a contradiction, since $\mathrm{x}_{\mathrm{B}}$ satisfies this condition for $\mathrm{x}_{\mathrm{B}}{ }_{\mathrm{B}}$. 
We conclude from the lemma above that those pairs $<x_{A}, x_{C}>$ of $R_{B}{ }^{m a x}$ that are in $\mathrm{R}_{\mathrm{B}}{ }^{\text {incompatible }}$ do not contribute to the realization of $\mathrm{R}_{\mathrm{C}}{ }^{\text {prod }}$. We therefore may eliminate from the solution $R_{B}{ }^{\max }$ all pairs in $R_{B}{ }^{\text {incompatible }}$ and still obtain the same set $R_{C}{ }^{\text {prod }}$ of realizable pairs $\left\langle x_{A}, x_{B}>\right.$. We call this the reduced maximal solution to the equation solving problem. It is characterized by the following predicate:

$$
\begin{aligned}
\mathrm{C}_{\mathrm{B}}{ }^{\text {red }}\left(\mathrm{x}_{\mathrm{A}}, \mathrm{x}_{\mathrm{C}}\right)= & \left(\exists \mathrm{x}_{\mathrm{B}} \in \mathrm{D}_{\mathrm{B}}: \mathrm{C}_{\mathrm{A}}\left(\mathrm{x}_{\mathrm{B}}, \mathrm{x}_{\mathrm{C}}\right) \wedge \mathrm{C}_{\mathrm{C}}\left(\mathrm{x}_{\mathrm{A}}, \mathrm{x}_{\mathrm{B}}\right)\right) \wedge \\
& \left(\neg \exists \mathrm{x}_{\mathrm{B}} \in \mathrm{D}_{\mathrm{B}}: \mathrm{C}_{\mathrm{A}}\left(\mathrm{x}_{\mathrm{B}}, \mathrm{x}_{\mathrm{C}}\right) \wedge \neg \mathrm{C}_{\mathrm{C}}\left(\mathrm{x}_{\mathrm{A}}, \mathrm{x}_{\mathrm{B}}\right)\right)
\end{aligned}
$$

\section{Submodule Construction for Synchronous Systems and LTS}

State machines are often used as models for reactive systems that interact with their environment. Often one considers a system model which is the composition of several state machines. Therefore a state machine is normally a component within a system, it interacts with other components of the system and possibly also with the environment of the system; or the state machine represents the interactions of the whole system with its environment. Because of space limitations, this sections is much condensed. More details can be found in [3].

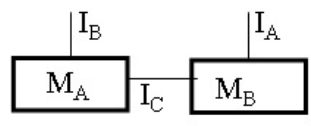

(a)

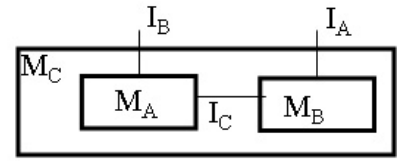

(b)

Fig. 1. (a) Two communicating components; (b) Submodule construction problem

A system component has one or more interfaces where interactions with the environment of the component take place. Each interface $\mathrm{i}$ is associated with a domain $\mathrm{I}_{\mathrm{i}}$; the elements of $I_{i}$ are the possible interactions that may take place at that interface. We write $\mathrm{x}_{\mathrm{i}}{ }^{(\mathrm{t})}$ for the interaction that takes place at interface $\mathrm{i}$ at time unit t. Clearly, $\mathrm{x}_{\mathrm{i}}{ }^{(\mathrm{t})} \in \mathrm{I}_{\mathrm{i}}$ for all $\mathrm{t}$. We write $\mathrm{x}_{\mathrm{i}}$ for a sequence of interactions at interface $\mathrm{i}$ over a certain time period. We write $\mathrm{I}_{\mathrm{i}}{ }^{*}$ for the set of all sequences that can be formed by concatenating interactions from the domain $\mathrm{I}_{\mathrm{i}}$. We have $\mathrm{X}_{\mathrm{i}} \in \mathrm{I}_{\mathrm{i}}{ }^{*}$.

We assume trace semantics for the specification of the dynamic behaviour of a system, that is, the dynamic behavior of a system $M$ is defined in terms of the set of possible execution histories that could occur during the execution of the component. For a system with $\mathrm{n}$ interfaces $\mathrm{i}(\mathrm{i}=1, \ldots, \mathrm{n})$, an execution history consists of a tuplet $\left.<\mathrm{x}_{1}, \mathrm{x}_{2}, \ldots \mathrm{x}_{\mathrm{n}}\right\rangle$ where $\mathrm{x}_{\mathrm{i}}(\mathrm{i}=1, \ldots, \mathrm{n})$ is the sequence of interactions that occurred at interface $\mathrm{i}$ during the execution history. We therefore assume that the specification $\mathrm{S}$ of the behavior of $\mathrm{M}$ is given in the form of a (normally infinite) set of such tuplets. As in Section 2, instead of talking about the set $\mathrm{S}$ of tuplets, one may also talk about the predicate $\mathrm{C}$ that characterizes this set. 


\subsection{Submodule Construction for Synchronous Systems}

For synchronous systems, there is an interaction at each interface during each global time unit. Therefore, for a system as shown in Figure 1(b), the formula

$$
\forall<\mathrm{x}_{\mathrm{A}}, \mathrm{x}_{\mathrm{B}}, \mathrm{x}_{\mathrm{C}}>\in \mathrm{U}: \mathrm{C}_{\mathrm{A}}\left(\mathrm{x}_{\mathrm{B}}, \mathrm{x}_{\mathrm{C}}\right) \wedge \mathrm{C}_{\mathrm{B}}\left(\mathrm{x}_{\mathrm{A}}, \mathrm{x}_{\mathrm{C}}\right) \Rightarrow \mathrm{C}_{\mathrm{C}}\left(\mathrm{x}_{\mathrm{A}}, \mathrm{x}_{\mathrm{B}}\right)
$$

states that the traces of the composition of machines $M_{A}$ and $M_{B}$ are included in the traces of $\mathrm{M}_{\mathrm{C}}$. In order to compare this formula with what has been discussed previously in the literature, we have to introduce the hiding operator. When one of the interfaces (say i) is hidden, we obtain a visible behaviour which only involves the non-hidden interfaces. For a behavior $\mathrm{C}$ of a machine with $\mathrm{n}$ interfaces, we use the notation "hide ${ }_{\mathrm{i}}^{\text {(syn) }}\left(\mathrm{C}\left(\mathrm{x}_{1}, \mathrm{x}_{2}, \ldots \mathrm{x}_{\mathrm{n}}\right)\right.$ " to represent the predicate of the behaviour when interface $\mathrm{i}$ is hidden. As discussed by Abadi and Lamport, this predicate has the following form:

$$
\begin{aligned}
& <\mathrm{x}_{1}, \ldots, \mathrm{x}_{\mathrm{i}-1}, \mathrm{x}_{\mathrm{i}+1}, \ldots, \mathrm{x}_{\mathrm{n}}>\in \operatorname{hide}_{\mathrm{i}}^{(\mathrm{syn})}\left(\mathrm{C}\left(\mathrm{x}_{1}, \mathrm{x}_{2}, \ldots \mathrm{x}_{\mathrm{n}}\right)\right) \\
& \quad \text { iff } \exists \mathrm{x}_{\mathrm{i}} \in \mathrm{I}_{\mathrm{i}} *:<\mathrm{x}_{1}, \ldots, \mathrm{x}_{\mathrm{i}-1}, \mathrm{x}_{\mathrm{i}}, \mathrm{x}_{\mathrm{i}+1}, \ldots, \mathrm{x}_{\mathrm{n}}>\in \mathrm{C}\left(\mathrm{x}_{1}, \mathrm{x}_{2}, \ldots \mathrm{x}_{\mathrm{n}}\right)
\end{aligned}
$$

We note that $\left(1^{\text {syn }}\right)$ has the form of $\left(1^{\text {Pred }}\right)$ and we can follow the derivations of Sections 2.3 through 2.5. Using the above formula for hiding, we can rewrite Equation (5) of Section 2 for the reduced maximal solution as follows:

$$
\begin{aligned}
\mathrm{C}_{\mathrm{B}}{ }^{\text {red }}\left(\mathrm{x}_{\mathrm{A}}, \mathrm{x}_{\mathrm{C}}\right)=\operatorname{hide}^{(\mathrm{syn})}\left(\mathrm{C}_{\mathrm{A}}\left(\mathrm{x}_{\mathrm{B}}, \mathrm{x}_{\mathrm{C}}\right) \wedge \mathrm{C}_{\mathrm{C}}\left(\mathrm{x}_{\mathrm{A}}, \mathrm{x}_{\mathrm{B}}\right)\right) \\
\backslash \operatorname{hide}^{(\mathrm{syn})}{ }_{\mathrm{B}}\left(\left(\mathrm{C}_{\mathrm{A}}\left(\mathrm{x}_{\mathrm{B}}, \mathrm{x}_{\mathrm{C}}\right) \wedge\left(\mathrm{I}_{\mathrm{A}} * \times \mathrm{I}_{\mathrm{B}} * \backslash \mathrm{C}_{\mathrm{C}}\left(\mathrm{x}_{\mathrm{A}}, \mathrm{x}_{\mathrm{B}}\right)\right)\right)\right.
\end{aligned}
$$

\subsection{Submodule Construction for Interleaving Semantics}

In this modeling framework, we also have rendezvous interactions at interfaces, but interleaving semantics is assumed, which means that at most one interaction (on a single interface) may occur during each time unit. We use in the following the same modelling framework as for synchronous machines, but introduce the following changes:

- We allow an interface to have the value null during a given time unit, which means that no interaction takes place at this interface during this time unit.

- In a system of several components with $\mathrm{n}$ interfaces, a possible execution history $<\mathrm{x}_{1}, \mathrm{x}_{2}, \ldots \mathrm{x}_{\mathrm{n}}>$ must satisfy the following constraint, called interleaving constraint:

$$
\mathrm{IC}\left(\mathrm{x}_{1}, \mathrm{x}_{2}, \ldots \mathrm{x}_{\mathrm{n}}\right)=\text { for all } \mathrm{t}: \mathrm{x}_{\mathrm{i}}^{(\mathrm{t})} \in \mathrm{I}_{\mathrm{i}} \text { implies } \mathrm{x}_{\mathrm{j}}^{(\mathrm{t})}=\text { null for all } \mathrm{j} \neq \mathrm{i} \text {. }
$$

We say that two execution histories are equivalent if they exhibit the same sequence of non-null interactions. This leads to the following formula of interface hiding:

$$
\begin{aligned}
& <\mathrm{x}_{1}, \ldots, \mathrm{x}_{\mathrm{i}-1}, \mathrm{x}_{\mathrm{i}+1}, \ldots, \mathrm{x}_{\mathrm{n}}>\in \operatorname{hide}^{(\mathrm{LTS})}{ }_{\mathrm{i}}\left(\mathrm{C}\left(\mathrm{x}_{1}, \mathrm{x}_{2}, \ldots \mathrm{x}_{\mathrm{n}}\right)\right) \\
& \text { iff } \operatorname{IC}\left(x_{1}, \ldots, x_{i-1}, x_{i+1}, \ldots, x_{n}\right) \\
& \wedge \exists<x_{1}{ }^{6}, \ldots, x_{i-1}{ }^{6}, x_{i}{ }^{6}, x_{i+1}{ }^{6}, \ldots, x_{n}{ }^{6}>:\left(\operatorname{IC}\left(x_{1}{ }^{6}, \ldots, x_{i-1}{ }^{6}, x_{i}{ }^{6}, x_{i+1}{ }^{6}, \ldots, x_{n}{ }^{6}\right)\right. \\
& \wedge<\mathrm{x}_{1}{ }^{6}, \ldots, \mathrm{x}_{\mathrm{i}-1}{ }^{\natural}, \mathrm{x}_{\mathrm{i}+1}{ }^{6}, \ldots, \mathrm{x}_{\mathrm{n}}{ }^{\circ}>\cong<\mathrm{x}_{1}, \ldots, \mathrm{x}_{\mathrm{i}-1}, \mathrm{x}_{\mathrm{i}+1}, \ldots, \mathrm{x}_{\mathrm{n}}> \\
& \left.\wedge<\mathrm{x}_{1}{ }^{6}, \ldots, \mathrm{x}_{\mathrm{i}-1}{ }^{6}, \mathrm{x}_{\mathrm{i}}{ }^{6}, \mathrm{x}_{\mathrm{i}+1}{ }^{6}, \ldots, \mathrm{x}_{\mathrm{n}}{ }^{6}>\in \mathrm{C}\left(\mathrm{x}_{1}, \mathrm{x}_{2}, \ldots \mathrm{x}_{\mathrm{n}}\right)\right)
\end{aligned}
$$


Because of the interleaving constraint, the formulas $\left(1^{\mathrm{syn}}\right)$ and (2) become:

$$
\begin{aligned}
& \forall<\mathrm{x}_{\mathrm{A}}, \mathrm{x}_{\mathrm{B}}, \mathrm{x}_{\mathrm{C}}>\in \mathrm{U}: \mathrm{IC}\left(\mathrm{x}_{\mathrm{A}}, \mathrm{x}_{\mathrm{B}}, \mathrm{x}_{\mathrm{C}}\right) \wedge \mathrm{C}_{\mathrm{A}}\left(\mathrm{x}_{\mathrm{B}}, \mathrm{x}_{\mathrm{C}}\right) \wedge \mathrm{C}_{\mathrm{B}}\left(\mathrm{x}_{\mathrm{A}}, \mathrm{x}_{\mathrm{C}}\right) \Rightarrow \mathrm{C}_{\mathrm{C}}\left(\mathrm{x}_{\mathrm{A}}, \mathrm{x}_{\mathrm{B}}\right) \quad\left(1^{\text {LTS }}\right) \\
& \mathrm{C}_{\mathrm{B}}{ }^{\max }\left(\mathrm{x}_{\mathrm{A}}, \mathrm{x}_{\mathrm{C}}\right)=\mathrm{IC}\left(\mathrm{x}_{\mathrm{A}}, \mathrm{x}_{\mathrm{C}}\right) \wedge \forall<\mathrm{x}_{\mathrm{A}}{ }^{6}, \mathrm{x}_{\mathrm{B}}{ }^{6}, \mathrm{x}_{\mathrm{C}}{ }^{\circ}>\in \mathrm{U}: \\
& \mathrm{IC}\left(\mathrm{x}_{\mathrm{A}}{ }^{\prime}, \mathrm{x}_{\mathrm{B}}{ }^{6}, \mathrm{x}_{\mathrm{C}}{ }^{6}\right) \wedge<\mathrm{x}_{\mathrm{A}}{ }^{\prime}, \mathrm{x}_{\mathrm{C}}{ }^{\circ}>\cong<\mathrm{x}_{\mathrm{A}}, \mathrm{x}_{\mathrm{C}}>\wedge \mathrm{C}_{\mathrm{A}}\left(\mathrm{x}_{\mathrm{B}}{ }^{6}, \mathrm{x}_{\mathrm{C}}{ }^{6}\right) \Rightarrow \mathrm{C}_{\mathrm{C}}\left(\mathrm{x}_{\mathrm{A}}{ }^{6}, \mathrm{x}_{\mathrm{B}}{ }^{6}\right) \quad\left(2^{\mathrm{LTS}}\right)
\end{aligned}
$$

And the reduced maximal solution becomes

$$
\begin{aligned}
\mathrm{C}_{\mathrm{B}}{ }^{\text {red }}\left(\mathrm{x}_{\mathrm{A}}, \mathrm{x}_{\mathrm{C}}\right)= & \operatorname{hide}^{(\mathrm{LTS})}{ }_{\mathrm{B}}\left(\mathrm{C}_{\mathrm{A}}\left(\mathrm{x}_{\mathrm{B}}, \mathrm{x}_{\mathrm{C}}\right) \wedge \mathrm{C}_{\mathrm{C}}\left(\mathrm{x}_{\mathrm{A}}, \mathrm{x}_{\mathrm{B}}\right)\right. \\
& \wedge \neg \operatorname{hide}^{(\mathrm{LTS})}{ }_{\mathrm{B}}\left(\mathrm{C}_{\mathrm{A}}\left(\mathrm{x}_{\mathrm{B}}, \mathrm{x}_{\mathrm{C}}\right) \wedge \neg \mathrm{C}_{\mathrm{C}}\left(\mathrm{x}_{\mathrm{A}}, \mathrm{x}_{\mathrm{B}}\right)\right)
\end{aligned}
$$

This solution was presented (using a different notation) in [1], which was the first paper on submodule construction to our knowledge. We note that this formula is the same as $\left(5^{\mathrm{syn}}\right)$, except that a different hiding operator is used.

\section{Conclusions}

We have shown in this paper that the problem of submodule construction can be formulated in a general setting using first-order logic. It turns out that solutions to this problem in logic are quite simple, and they can be mapped (together with their proof of correctness) into the different specification formalisms considered in earlier work. Therefore this paper provides, in a sense, new proofs of correctness for the solutions of the submodule construction problem described earlier.

We consider in this paper trace semantics, that is, the behaviour of the system, or of a component, is characterized by the set of possible execution histories. This is adequate for safety properties, but ignores issues of liveness, progress, absence of deadlocks and fairness.

It is to be noted that the complexity of the algorithms for constructing the missing submodule depends on the specification formalism used. For state machines the complexity is polynomial if the interactions at the interface $\mathrm{I}_{\mathrm{C}}$ in Figure 1(b) are visible by $\mathrm{M}_{\mathrm{C}}$, however, if they are hidden, as we assume in this paper, the algorithms become exponential, because the hiding introduces non-determinism and the algorithm to find a deterministic automaton equivalent to a non-deterministic one is exponential. The problem becomes undecidable for behavior specifications in CSP.

\section{References}

[1] Bochmann, G.V., Merlin, P.M.: On the construction of communication protocols. In: ICCC, pp. 371-378 (1980); reprinted in Communication Protocol Modeling, Sunshine, C.(ed.). Artech House Publ., (1981); russian translation: Problems of Intern. Center for Science and Techn. Information, vol. 2, Moscow, pp. 146-155 (1981)

[2] Merlin, P., Bochmann, G.V.: On the Construction of Submodule Specifications and Communication Protocols. ACM Trans. on Programming Languages and Systems 5(1), 1-25 (1983)

[3] Extended version of this paper, http: //www.site.uottawa.ca/ bochmann/dsrg/PublicDocuments / Publications/Boch09a.pdf

[4] Ramadge, P.J.G., Wonham, W.M.: The control of discrete event systems. Proceedings of the IEEE 77(1) (January 1989)

[5] Bochmann, G.V.: Submodule construction - the inverse of composition (submitted) 